\title{
Mitteilungen
}

\section{Herausgeberwechsel in der Germanischen Abteilung}

Mit diesem Band der Germanistischen Abteilung hat Prof. Dr. Dr. h. c. Adolf Laufs nach 23 Jahrgängen die Redaktion der ZRG zurückgelegt. Mitarbeiter und Verlag sagen herzlichen Dank für die verdienstvollen Jahre!

Die Herausgabe der Aufsätze hat Prof. Dr. Elmar Wadle, Saarbrücken, übernommen. Den Literaturteil der Germanistischen Abteilung verwaltet nun Prof. Dr. Gerhard Köbler, Deutsche und Österreichische Rechtsgeschichte, Bürgerliches Recht und Handelsrecht, Innrain 52, A-6020 Innsbruck.

\section{Todesnachrichten}

Der langjährige verdienstvolle Alt-Herausgeber dieser Abteilung, Prof. Dr. Dres. h. c. mult. Hans Thieme verstarb am 3. Oktober 2000 im 95. Lebensjahr in Freiburg im Breisgau.

Am 24. Mai 2000 verstarb in München Prof. Dr. Dres. h. c. Sten Gangér. Im September 1998 verstarb in Zürich im 94. Lebensjahr Prof. Dr. Dres. h. c. Karl Siegfried Bader, der zeitweilig Herausgeber sogar zweier Abteilungen dieser Zeitschrift war.

Nachrufe auf Edith Ennen und Nikolaus Grass finden sich oben in diesem Band der ZRG.

\section{Generalregister der Bände 76-100}

Das seit langem von Frau Dr. jur. Bettina Kern, Leipzig, bearbeitete umfangreiche Gesamtregister der Bände 76-100 der Germanistischen Abteilung (Personen-, Sachund Quellenverzeichnisse) steht kurz vor dem Abschluß. Es wird bei Erscheinen den Abonnenten der Germanistischen Abteilung der ZRG unaufgefordert zugeschickt werden, aber auch einzeln käuflich sein. 